\title{
Akım Kuraklık İndeksi Yönteminin Farklı Zaman Ölçekleri İçin Hidrolojik Olarak Değerlendirilmesi: Arsuz Ovası Örnek Çalışması
}

\author{
Evren Turhan ${ }^{1,}{ }^{*}$, Buse Duyan Çulha ${ }^{2}$, Serin Değerli1 ${ }^{1}$ \\ ${ }^{1}$ Adana Alparslan Türkeş Bilim ve Teknoloji Üniversitesi, Mühendislik Fakültesi, Inşaat Mühendisliği, 01250, Adana. \\ ${ }^{2}$ Adana Su ve Kanalizasyon Idaresi Genel Müdürlüğü, Plan-Proje Dairesi Başkanlığı, İçme Suyu Şube Müdürlüğü, 01140, Adana.
}

\section{Özet}

Kuraklıkların süreleri ve şiddetlerine bağlı olarak ortaya çıkan etkileri nedeni ile kuraklık uzun süredir öncelikli konular arasında yer almaktadır. Hidrolojik kuraklık iklim değişikliği sonucu ortaya çıkan doğada faydalanabileceğimiz temiz su kaynaklarının azalması şeklinde ifade edilmektedir. Bu çalışmada Asi Nehri Havzası'nda tarımsal sit alanlarından biri olan Arsuz Ovası hidrolojik kuraklık analizi için uygulama alanı olarak tercih edilmiştir. Öncelikle birbirine yakın konumda bulunan D19A021, D19A022 ve D19A023 numaralı üç farklı Akım Gözlem İstasyonundan (AGI) elde edilen 1990-2015 yılları arası aylık ortalama akım verileri kullanılarak debi-zaman ve debi süreklilik ĕgrileri (DSE) olușturulmuștur. Yine aynı veriler yardımı ile 3, 6 ve 12 ay gibi farklı zaman ölçekleri için Akım Kuraklık Indeksi (AKI) değerleri hesaplanmıștır. Çalışma sonucunda, üç istasyonda da pik debi değerlerinin birkaç dönem haricinde birbirine oldukça yakın olduğu görülmüş̧ür. Tüm istasyonlar için 2000 yll itibariyle havzada Aşırı Kurak ve Aşırı Nemli dönemlerin gerçekleşmeye başladığı gözlemlenmiştir. En nemli dönem 2009 ile 2010 yılları arasında gerçekleşirken, en kurak dönem ise 2014 olarak dikkat çekmektedir. Kuraklı̆̆ın farklı zaman ölçeklerindeki seyri değerlendirildiğinde son yıllarda kurak dönem sayısında artış gerçekleşmektedir.

\section{Anahtar Sözcükler}

Hidrolojik Kuraklık, Akım Kuraklık İndeksi, İklim Değişikliği, Debi Süreklilik Eğrileri, Arsuz Ovası

\section{Hydrological Evaluation of Streamflow Drought Index Method for Different Time Scales: A Case Study of Arsuz Plain, Turkey}

\begin{abstract}
Drought has been among the priority issues for a long time because of its effects that vary depending on duration and severity. Hydrological drought can be explained as the decrease in clean water resources caused by climate change. In this paper, Arsuz Plain, one of the agricultural protected area in the Asi River Basin, was selected as the case study for the hydrological drought analysis. Firstly, discharge-time and flow duration curves $(F D C)$ were created by using monthly average discharge data between the years of 1990 and 2015 which were obtained from three different Flow Observation Stations (FOSs) (numbered D19A021, D19A022 and D19A023), located close to each other. With the help of these data, Streamflow Drought Index (SDI) values were calculated for different time scales such as 3, 6 and 12 months. Consequently, it has been seen that all three stations have similar results in terms of the peak flow rate values excluding a few periods. As of 2000, it has been observed that Extreme Drought and Extremely Wet periods have started to occur in the basin for these stations. While the most wet period began between the years 2009 and 2010, the driest period was 2014. Considering the course of the drought event in different time scales, it can be concluded that the number of dry periods has increased in recent years.
\end{abstract}

Keywords

Hydrological Drought, Streamflow Drought Index, Climate Change, Flow Duration Curves, Arsuz Plain

\section{Giriş}

Kuraklık, belirli bir zaman periyodu için yağışların normal seviyelerin altına düşmesi sebebi ile su kaynaklarının olumsuz olarak etkilendiği bir çevre sorunu olarak dikkat çekmektedir (Özfidaner vd. 2015, Dikici 2020). Yağış eksikliği meteorolojik kuraklık; yüzeysel veya yeraltı su potansiyelindeki eksiklikler ise hidrolojik kuraklık olarak ifade edilmektedir (Gümüş 2017). Tarımsal kuraklık yă̆ış̧, yüzeysel ve yeraltı su potansiyelinin tarım açısından azalması olarak tanımlanmaktadır (Dai vd. 2020). Kuraklık bir doğa olayı olarak kabul edilse dahi su kaynaklarının doğru ve efektif yönetimi bakımından hayati bir önemi bulunmaktadır. Kuraklığın olası olumsuz etkilerini minimum seviyeye indirebilmek amacıyla bölgesel ölçekte planlama çalışmalarının yapılması, özellikle gözlemlenmiş geçmiş verilerden faydalanılarak kuraklığın şiddet ve büyüklüğü ile ilgili sınıflandırmaların ortaya konulabilmesi ileriye yönelik tahminler yönünden büyük oranda katkı sunabilecektir. 
Kuraklığı nicel olarak değerlendirmenin en etkili yöntemi kuraklık indekslerinden yararlanmaktır. Bu sayede kuraklığın zamansal şiddet, büyüklük ve dağılım bakımından incelenmesi mümkün olabilecektir (Gümüş ve Algın 2017; Özfidaner ve Topaloğlu 2020). Meteorolojik ve hidrolojik kuraklığın belirlenebilmesi amacıyla çok farklı yöntemler kullanılabilmektedir. Genelde geçmiş yağış verileri ile hesaplanan Standartlaştırılmış Yağış İndeksi (SPI) ve Normalin Yüzdesi İndeksi (PNI) kuraklık analizi çalışmalarında yaygın olarak ele alınmaktadır (Eriş vd. 2020; Keskiner vd. 2020; Oğuz vd. 2021; Şener ve Şener 2021). Palmer Kuraklık Şiddeti İndeksi (PDSI), De Martonne Indeksi, Erinç Kuraklık İndeksi ve Aydeniz Kuraklık İndeksi sadece yağış verileri değil aynı zamanda sıcaklık ve nem gibi birçok meteorolojik parametreler için de kullanılabilmektedir (Arslan vd. 2014; Keskiner vd. 2019; Başakın vd. 2019; Partal ve Yavuz 2020). Ayrıca hidrolojik kuraklığın izlenmesinde bu çalışma kapsamında ele alınan Akım Kuraklık İndeksi (AKİ) kullanılmaktadır. AKİde gözlenmiş akım verileri giriş parametresi olarak değerlendirilmektedir (Gümüş 2017; Gümüş vd. 2018; Özkaya ve Zerberg 2019; Yaltı ve Aksu 2019; Eroğluer ve Apaydın 2020; Kumanlığlu 2020; Jahangir ve Yarahmadi 2020; Altın vd. 2020; Aghelpour vd. 2021). Kuraklığın izlenmesi ve ileriye dönük tahmin modellerinin oluşturulabilmesi için AKİ'nin farklı zaman ölçeklerinde sayısal olarak araştırılmasının ihtiyaç duyulan çalışmalardan biri olduğu ifade edilmektedir (Adib vd. 2020).

AKİ yöntemi yalnızca aylık ortalama akım verileri ile hesaplanabilmektedir (Nalbantis 2008; Tabari vd. 2013; Özcan vd. 2019). Kuraklık ile ilgili en temel problemlerden biri kurak dönem boyunca sadece yağış verileri ile analiz edilen kuraklık indislerinin değil, kuraklığın diğer indislerle de incelenmesi gerekliliğidir. Gümüş (2017) yapmış olduğu çalışmada Asi Havzası'nın AKİ ile hidrolojik kuraklık analizi üzerine yoğunlaşmıştır. E19A005, E19A006, E19A007 ve E19A008 şeklinde dört ayrı akım gözlem istasyonu verilerinden faydalanmıştır. Aşağı Küçük Asi Havzası'nı uygulama yeri olarak değerlendirmiştir. Topçu ve Seçkin (2019) aynı istasyonlar için AKİ ile birlikte Bölgesel frekans analizi ve Lmomentler gibi farklı yöntemler kullanarak kuraklık analizi üzerine çalışmışlardır.

Dikici (2019) yaptığı çalışmada Asi Havzası için 1970-2016 yılları arası meteorolojik, hidrolojik ve hidrojeolojik verileri kullanarak kuraklık eğilimini incelemiştir. Havza geneli için akım eğilimleri bakımından bir azalma olmadığını belirtmekle birlikte belirli güvenilirlik düzeyinde istatistiki açıdan anlamlı olmasa dahi bir azalma olduğunu ifade etmiştir. Havzada özellikle Arsuz Ovası gibi aşağı kesimlerinde azalan su kaynaklarını ve artan kirlilik durumlarını önemli problemler olarak belirtmektedir. D19A021, D19A022 ve D19A023 Akım Gözlem İstasyonu (AGİ) verileri ile 19702015 yılları arasında toplam akımlar bakımından hidrolojik eğilim analizleri yapmıştır. Mann-Kendal trend analizi yöntemini uygulamış, sonuç olarak söz konusu AGİ'ler için \%95 güven düzeyinde istatistiki açıdan anlamlı ve azalan bir eğilim görülmediğine dikkat çekmiştir. Fakat yıllık toplam akımların zaman serisi ele alındığında, mevcut güven düzeyinde istatistiksel açıdan anlamlı olmasa bile bir azalma olduğunu da vurgulamaktadır. Bu bağlamda Arsuz Ovası için geçmiş veri kayıtları ile AKİ yönteminden yararlanarak hidrolojik kuraklık analizinin gerçekleştirilmesi sonucunda havzanın kuraklık hassasiyetinin belirlenebileceği; kuraklık öncesi, esnası ve sonrasında yapılacak çalışmalar ve alınması gerekli önlemlerin ele alınacağı ileriye dönük projeksiyon çalışmaları, eylem planları ve birçok çalışma açısından oldukça faydalı olabilecektir.

Bu çalışma kapsamında Asi Nehri Havzası'nda verimli tarım alanlarına sahip Arsuz Ovası'ndaki kuraklığın hidrolojik yönden değerlendirilmesi amaçlanmıştır. Ovanın tüm havza içerisindeki yüzölçümü oranı, akış katsayıları ve diğer dış etkenler yani tüm tüketim verileri (sulama, içme-kullanma ve buharlaşma gibi) değişimleri göz önüne alındığında Asi Nehri Havzası'nın tamamına oranla oldukça düşük bir katsayı değeri elde edildiği için Akım Gözlem İstasyonlarına (AGİ) ait akım değerleri doğal akımlar olarak değerlendirilmiştir. Öncelikle 26 y1llık (1990-2015) gözlemlenmiş veriler (DSI 2018) kullanılarak debi-zaman grafikleri oluşturulmuştur. Daha sonra D19A021, D19A022 ve D19A023 akım gözlem istasyonlarına ait debi süreklilik eğrileri çizilerek belirli debi değerlerinin aşılma olasılıkları irdelenmiştir. Söz konusu gözlem istasyonları verilerinden faydalanılarak hidrolojik kuraklık analizi yapılmıştır. Kuraklık indislerinden Akım Kuraklık İndeksi (AKİ) yöntemi kullanılmış olup; literatürde sıklıkla incelenen 3, 6 ve 12 ay gibi farklı zaman ölçekleri ele alınmıştır. Uzun zaman sürecindeki indis değerlerinin bahsi geçen ölçeklerdeki değişimleri ortaya konmaya çalışılmıştır. Elde edilen sonuçlar ileride değerlendirilebilecek akım tahminleri ve kuraklık durumuna karşı alınabilecek tedbirler açısından gelecek çalışmalarına işık tutabilecektir.

\section{Materyal ve Yöntem}

\section{1. Çalışma Alanı}

Türkiye’nin güneyinde yer alan Asi Nehri Havzası yaklaşık $7800 \mathrm{~km}^{2}$ drenaj alanı ve komşu ülkelerle sınır özelliği göstermesi sebebiyle önem derecesi yüksek havzalardan biri olarak düşünülmektedir (Şekil 1) (TOB 2019). Havza, Türkiye'nin 26 havzasından biri olup; Hatay, Kilis, Gaziantep, Adana ve Osmaniye illerinin tamamını veya büyük bir bölümünü içermektedir (Dikici 2019). 


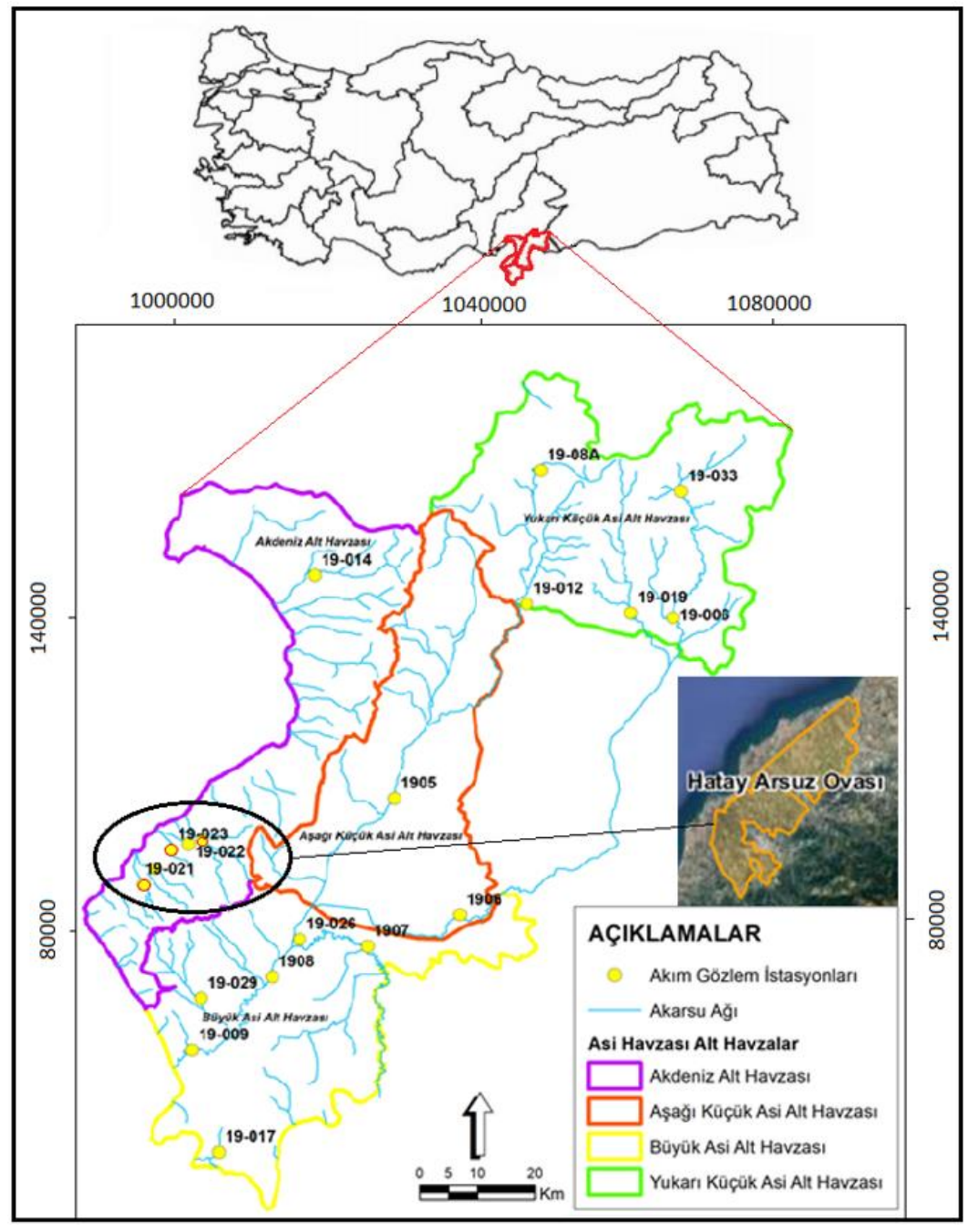

Şekil 1: Asi havzası lokasyonu (TOB 2019)

Asi Nehri'nden çoğunlukla tarımsal sulama amacıyla faydalanılmakta ve yaz aylarında havzadaki birçok nehir kuruyabilmektedir (Kılıç 2017). Arsuz Ovası, Hatay ili Arsuz ilçesi sınırlarında bulunmaktadır. Batıda Akdeniz, doğuda Amanos Dağları, kuzeyde İskenderun, güneyde ise Samandağ ilçesi ile çevrilidir. Yazları sıcak ve kurak, kışları ılık ve yağışı olan Akdeniz iklimi hakimdir (Uludağ ve Ağca 2019). Asi Nehri Havzası'nda 1963 yılından itibaren DSİ tarafından işletilen AGI'ler mevcuttur. Bu çalışmada kuraklığın değerlendirilebilmesi adına Arsuz Ovası içerisinde yer alan Avcılar Suyu, Beyköy Suyu ve Hacı Ahmetli Deresi üzerinde kurulmuş sırasıyla D19A021, D19A022 ve D19A023 numaralı üç farklı AGİ tercih edilmiştir. Analizlerin yapıldığı AGİ'lerin bulunduğu akarsularda herhangi bir su alma yapısı (baraj, gölet vb.) bulunmamaktadır (TOB 2019). Tablo 1'de belirlenen istasyonların numaraları, adları, lokasyonları, yağış alanları ve gözlemlenmiş akım verilerinin yıllık ortalamaları gösterilmektedir (DSİ 2018).

Tablo 1: AGl'lerin bilgileri (DSI 2018)

\begin{tabular}{|c|c|c|c|c|c|c|}
\hline AGİ No & İstasyon Ad 1 & Enlem (K) & Boylam (D) & $\begin{array}{l}\text { Yăğış } \\
\text { Alanı } \\
\left(\mathrm{km}^{2}\right)\end{array}$ & $\begin{array}{c}\text { Ortalama } \\
\text { Ak1m } \\
\left(\mathrm{m}^{3} / \mathrm{s}\right)\end{array}$ & $\begin{array}{c}\text { Gözlem ve } \\
\text { Değerlendirme Süresi }\end{array}$ \\
\hline D19A021 & $\begin{array}{c}\text { Avcilar Suyu- } \\
\text { Avcilar }\end{array}$ & $36^{\circ} 21^{\prime} 19^{\prime \prime}$ & $35^{\circ} 54^{\prime} 5^{\prime \prime}$ & 27 & 1.052 & \multirow{3}{*}{ 1991-2015 Su Y1lları } \\
\hline D19A022 & $\begin{array}{c}\text { Beyköy Suyu- } \\
\text { Beyköy }\end{array}$ & $36^{\circ} 23^{\prime} 57^{\prime \prime}$ & $35^{\circ} 58^{\prime} 20^{\prime \prime}$ & 23 & 0.283 & \\
\hline D19A023 & $\begin{array}{c}\text { Hacı Ahmetli } \\
\text { Deresi- Ahmetli }\end{array}$ & $36^{\circ} 22^{\prime} 30^{\prime \prime}$ & $35^{\circ} 56^{\prime} 25^{\prime \prime}$ & 43 & 1.066 & \\
\hline
\end{tabular}

AKİ hesaplamalarında zaman aralığının eşdeğer olması açısından tüm istasyonlar için veri başlangıç yılı 1991, bitiş ise 2015 su yılı olarak seçilmiştir. 


\subsection{Akım Kuraklık İndeksi (AKi)}

Akım Kuraklık İndeksi (AKİ) aylık ortalama akım verilerinden faydalanılarak hesaplanabilmektedir. Akım verileri $\mathrm{Q}_{\mathrm{i}, \mathrm{j}}$ şeklinde gösterildiğinde sırası ile $i$ hidrolojik yıll, $j$ su yılı içerisindeki ay sayısını ve $k$ ise referans periyodunu ifade etmektedir. Nalbantis (2008) tarafından oluşturulmuş bu metotta kümülatif akım hacmi aşağıdaki Denklem 1'de olduğu gibi belirtilebilir:

$V_{i, k}=\sum_{j=1}^{3 k} Q_{i, j} \quad \mathrm{i}=1,2, \ldots \quad \mathrm{j}=1,2, \ldots, 12 \mathrm{k}=1,2,3,4$

Ekim-Aralık dönemi için k=1, Ekim-Mart dönemi için k=2, Ekim-Haziran için k=3 ve Ekim-Eylül için k=4 olarak değerlendirilmektedir. Örneğin $\mathrm{k}=2$ sırasıyla AKİ-Ekim (Ekim ayından başlamak üzere 6 ay) ve AKİ-Nisan (Nisan ayından başlamak üzere 6 ay), yıllık kuraklık indis değeri ise AKİ-12 olarak temsil edilmektedir. Kümülatif akım hacimlerine bağlı olarak, $i$ hidrolojik yılın her bir $k$ için AKİ değeri Denklem 2'deki gibi tanımlanabilmektedir (Altın vd. 2020):

$A K \dot{\mathrm{I}}_{i, k}=\frac{V_{i, k}-\overline{V_{k}}}{s_{k}}, k=1,2,3,4$

Denklem 2'deki $V_{k}$ ve $S_{k}$ sirasıyla kümülatif akım hacimlerinin ortalamasını ve standart sapma değerini göstermektedir. AKİ değerleri Aşırı Nemli ve Aşırı Kurak arasında sekiz farklı sınıflandırmaya ayrılmıştır. Tablo 2'de AKİ değerlerinin sınıflandırılmış halini görebilmek mümkündür (Hong vd. 2015).

Tablo 2: AKI sınıflandırması (Hong vd. 2015)

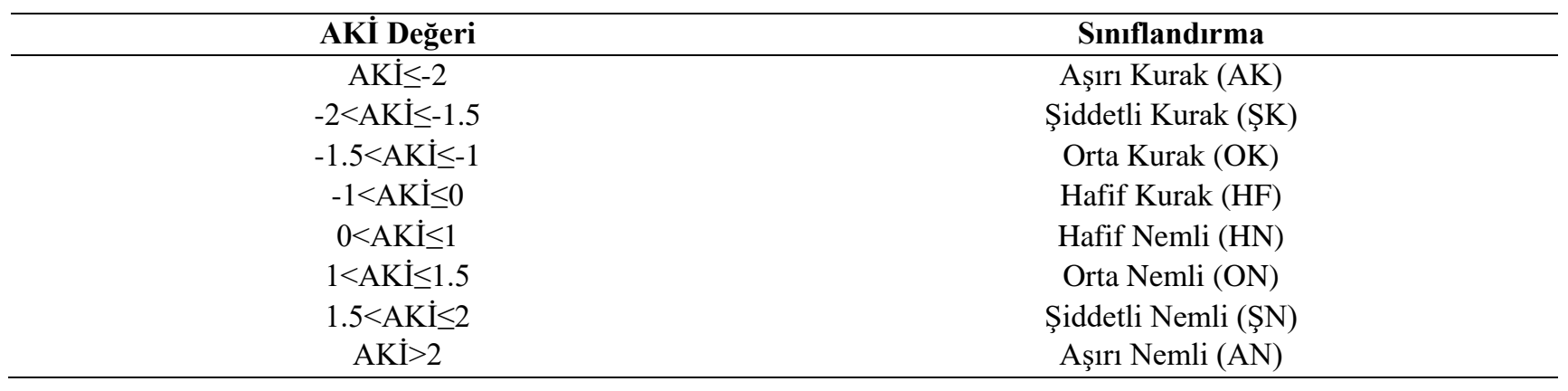

\section{Bulgular ve Tartışma}

\subsection{Debi-Zaman Grafikleri}

D19A021, D19A022 ve D19A023 nolu AGİ'lerinin aylı ortalama debilerinin zamanla değişimi Şekil 2'de gösterilmektedir.

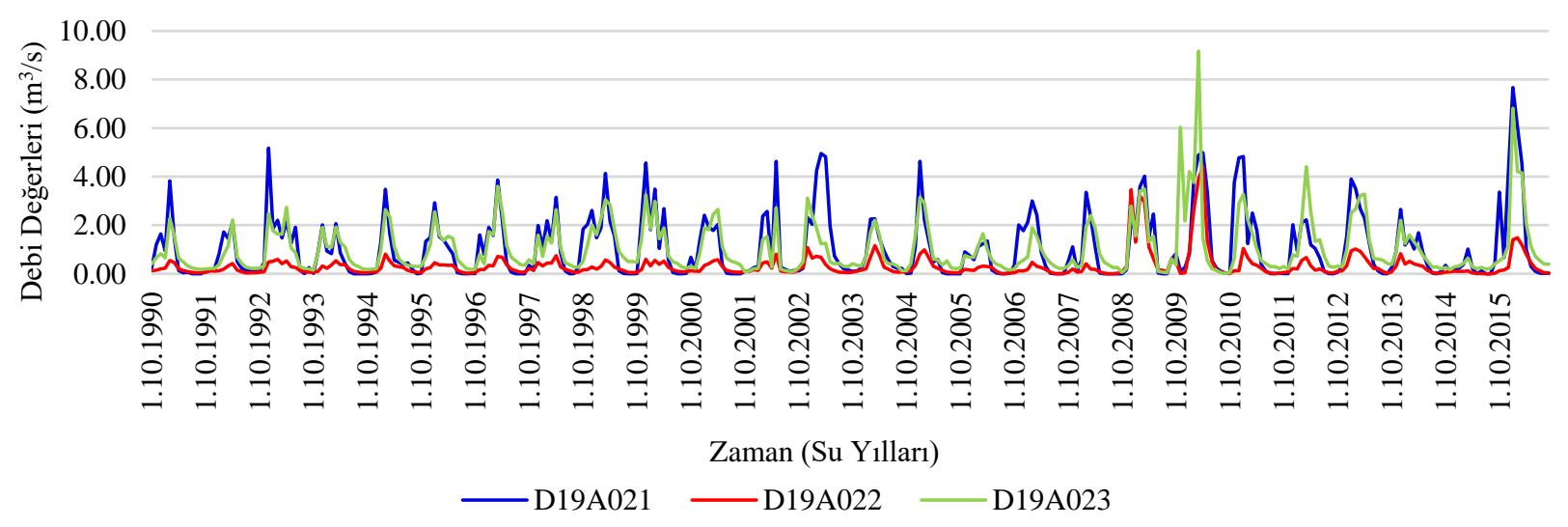

Şekil 2: Debi-zaman grafikleri (1990-2015 su yılları) 
Grafikler incelendiğinde D19A022 AGİ debi değerlerinin diğer iki istasyona kıyasla daha düşük seviyelerde seyrettiği görülebilmektedir. Buna rağmen üç istasyonda da pik debi değerlerinin birkaç dönem haricinde birbirine oldukça yakın olduğu söylenebilir. Ayrıca 2000 yılına kadar akım değerlerinde kısmen bir denge olduğu ve debilerin belirli değerleri aşmadığı gözlemlenebilmektedir, ancak 2000 yılı sonrasında akımlarda büyük farklılıklar göze çarpmaktadır. Özellikle 2009 yılında tüm istasyonlar için akım en yüksek değerde izlenmiş, 2014 yılında ise minimum değerlere kadar gerileme göstermiştir. Her üç istasyonun aylık akım verileri kullanılarak oluşturulan istatistiksel ilişkiler değerlendirildiğinde birbirine yakın sonuçların olduğu görülmüştür.

\subsection{Debi Süreklilik Eğrileri}

Debi süreklilik eğrisi (DSE); gözlenmiş akım verileri yardımı ile nehirlerde belli bir debi değerinin aşıldığı zaman yüzdesini ifade etmektedir (Eriş vd. 2019). Akarsuyun düşük akım karakteristiklerini temsil eden bu eğri ordinatta debi değeri, apsiste ise aşılma yüzdesi yer alacak şekilde çizilmektedir. DSE'nin minimum 25-30 yıl zaman periyodunda günlük akım verileri kullanılarak oluşturulması gerektiği belirtilmektedir (Tosunoğlu vd. 2017). Günlük akımlar yerine aylık akımların tercih edilmesi gerektiğinde ise büyük havza koşullarında debi çoğu zaman önemli derecede değişim göstermemektedir. Şekil 3’te söz konusu AGI'lerin DSE'leri görülebilmektedir.
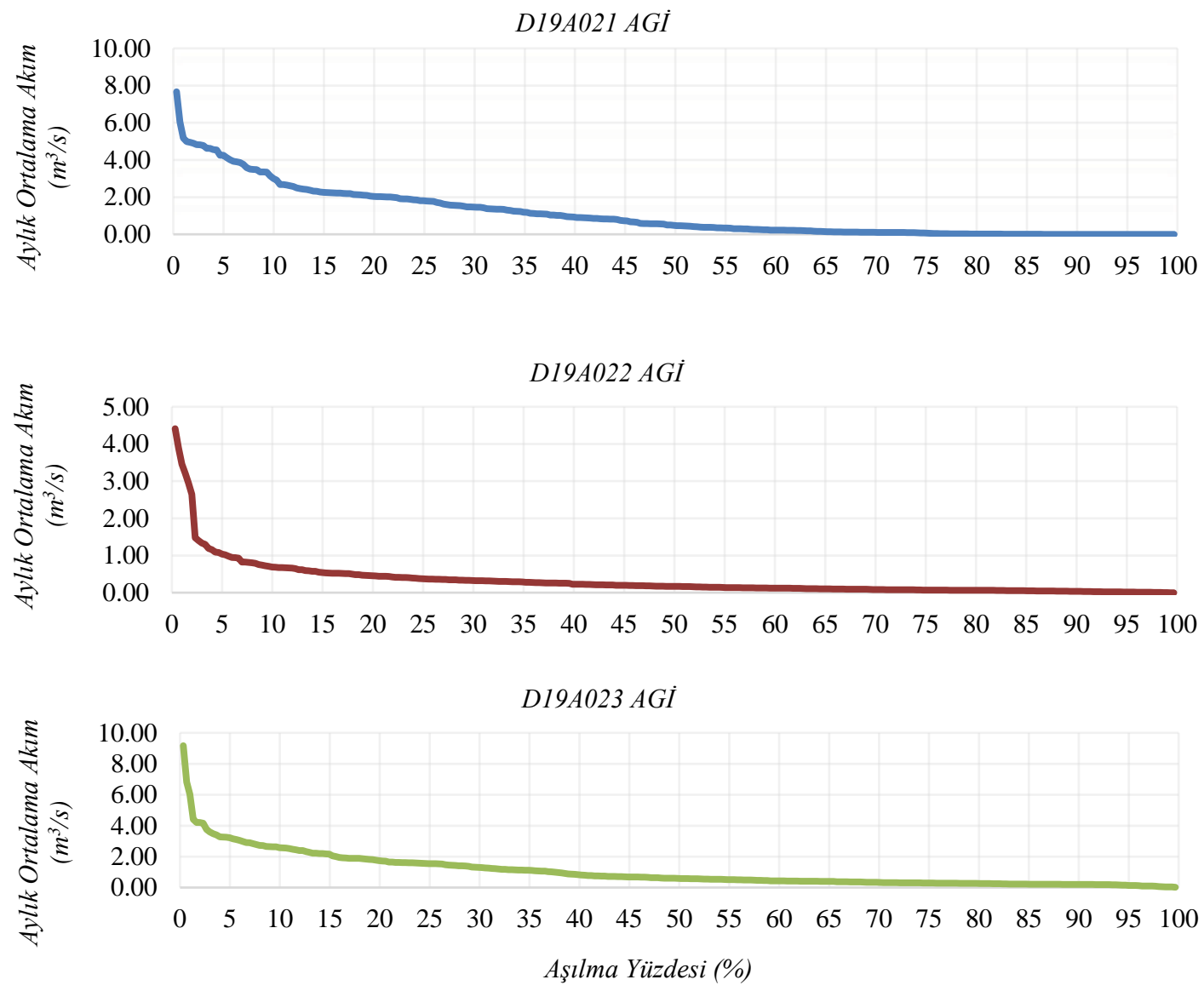

Şekil 3: Çalışma kapsamındaki AGl'lerin debi süreklilik eğrileri

DSE'ler 1990-2015 yılları arası aylık ortalama akım verileri kullanılarak oluşturulmuştur. Bu şekillerden görülebileceği üzere D19A022 AGİ için \%50 oranında DSE aş1lma yüzdesi diğer istasyonlara göre daha az akım değerlerinde mümkün olabilmektedir.

\subsection{Akım Kuraklık İndeksi (AKI) Sonuçları}

Asi Nehri Havzası-Arsuz Ovası Alt Havzası'nda bulunan D19A021, D19A022 ve D19A023 AGI'leri için 3, 6 ve 12 aylık farklı zaman dilimleri göz önüne alınarak AKİ değerleri hesaplanmıştır. Şekil 4'te elde edilen AKİ değerlerinin zamansal olarak değişimleri görülebilmektedir. Şekil 4’teki grafikler ele alındığında; AKİ-3 Ekim sonuçlarına göre 1992,2004 ve 2015 yıllarında Orta Kurak dönemler gözlemlenirken; 2002 yılında D19A023 AGİ için Şiddetli Kuraklık, 1995 yılında ise D19A021 AGİ için ise Aşırı Kurak dönem görülmüştür. 
AKİ-3 (Ekim)

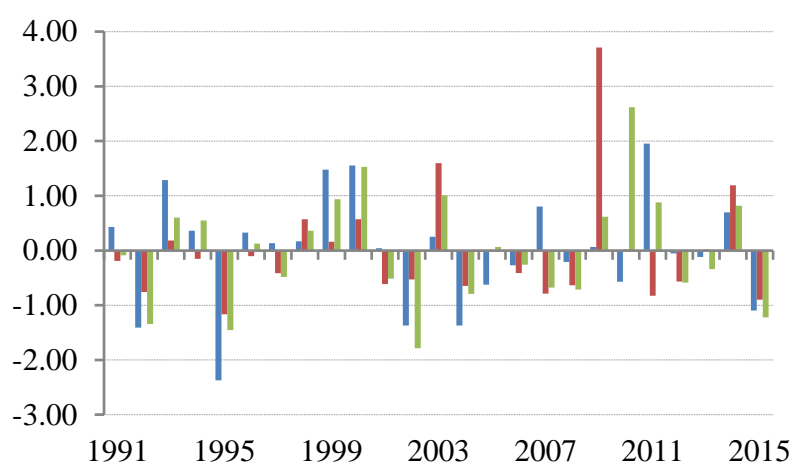

AKİ-3 (Nisan)

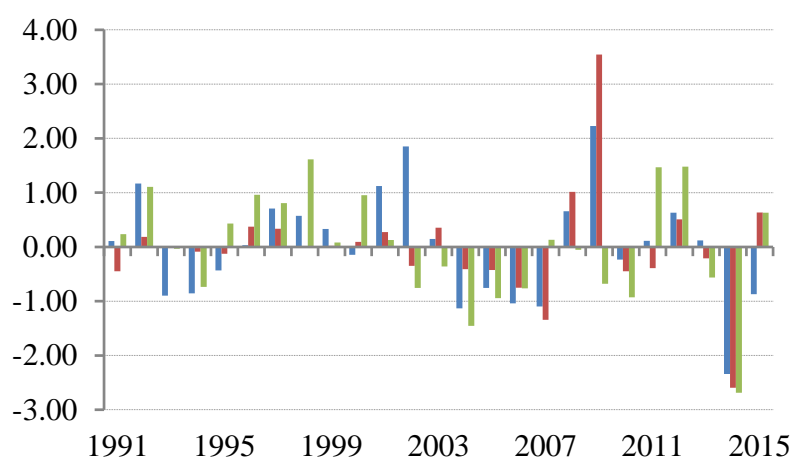

AKİ-6 Ekim

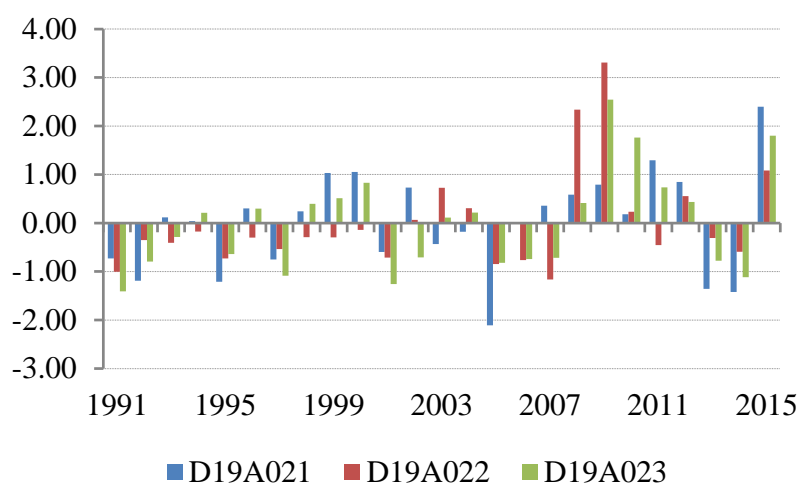

AKİ-3 (Ocak)

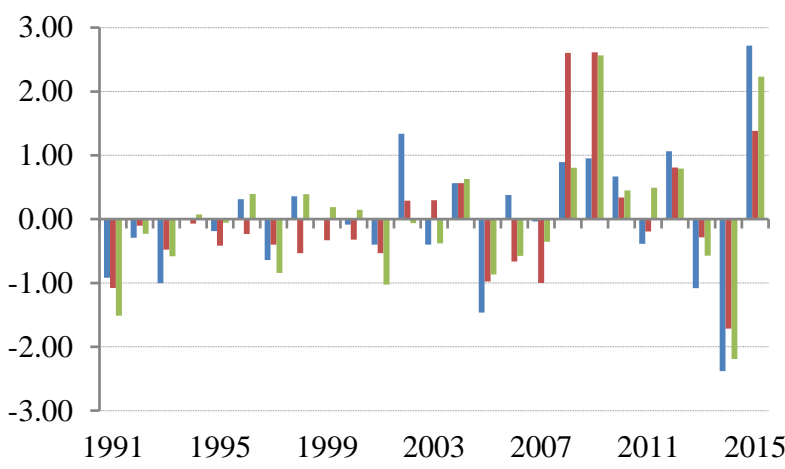

AKİ-3 (Temmuz)

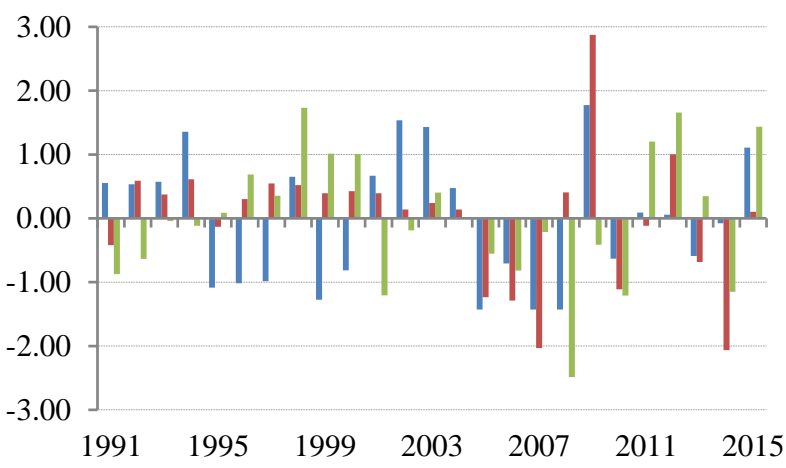

AKİ-6 Nisan

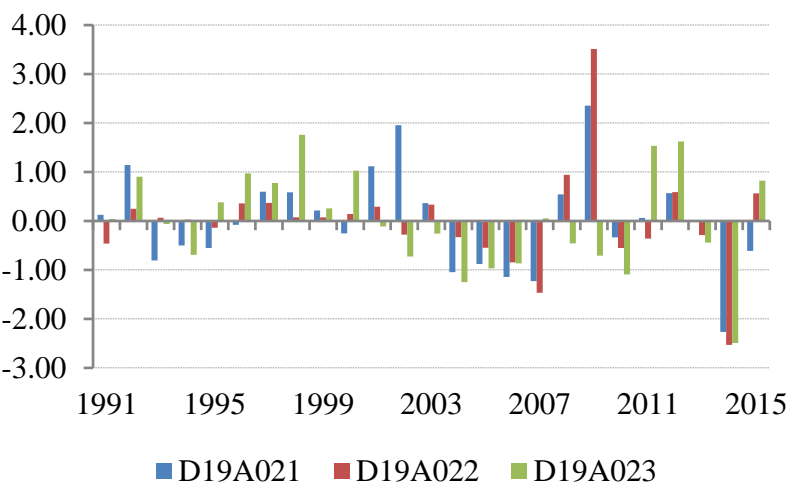

Şekil 4: AKI değerlerinin 1991-2015 su yılları için farklı zaman ölçeklerinde değişimi (AKi-3 ve AKI-6)

Gümüş̧ (2017), Topçu ve Seçkin (2019) tarafından yapılan çalışmalarda da aynı havzadaki farklı AGİ'lerde 2000 yılı sonrasında Aşırı Kurak dönemlere rastlanabilmektedir. Akım miktarının nispeten fazla olduğu AKİ-3 Ocak grafiğine bakıldığında 2014 yılında her üç AGİ için de Aşırı Kurak dönem meydana geldiği görülebilirken; 1991 ve 2005 yıllarında Orta Kurak dönemler tespit edilmiştir. Buna ek olarak AKİ-3 Ocak grafiğginde 2008, 2009 ve 2015 yılları için Aşıırı Nemli dönemler gözlemlenebilmektedir. Dikici (2019) çalışmasında son yıllarda yıllık toplam yağışlarının artan eğilimde olduğunu belirtmektedir. Bu ölçek için Aşırı Nemli dönemlerin olmasını bu durum ile izah edebilmek mümkündür.

AKİ-3 Nisan değerleri göz önüne alındığında ise 2014 yılında üç istasyonu da kapsayacak şekilde Aşırı Kurak dönem göze çarpmaktadır. 2009 yılında ise Aşırı Nemli durum gözlenmektedir. 2011 ve 2012 yıllarında Orta Nemli dönem söz konusudur. Yıllık akım değerlerinin en düşük düzeyde gözlemlendiği AKİ-3 Temmuz grafiğinde 2007, 2008 ve 2014 yıllarında Aşırı Kurak dönem ortaya çıkmıştır. AKİ-3 Temmuz grafiğinde bir tek Aşırı Nemli dönem 2009 yılı olarak ifade edilebilir. Kurak ve nemli dönemlerin belirtilen su yılları için bu zaman ölçeğinde daha homojen yayıldığı çıkarımı yapılabilir. Genel olarak tüm üç aylık zaman ölçeklerinde her istasyon için Aşırı Kurak ve Aşırı Nemli dönemlerin ortak olarak bulunduğu söylenebilir. 
Arsuz Ovası'nda 6 aylık zaman ölçekli hidrolojik kuraklığın analiz edilmesi için hazırlanan AKİ-6 Ekim grafiğine bakıldığında 2008, 2009 ve 2015 yılları Aşırı Nemli, 2005 yılı ise Aşırı Kurak olarak gözlenmiştir. Gümüş (2017), Topçu ve Seçkin (2019) çalışmalarında da istasyonların ortalama değerleri göz önüne alındığında 2001 yılı Aşırı Kurak dönem olarak ifade edilmektedir. Arsuz Ovası'nda Aşırı Kurak dönem 2005 yılı olarak farklı bir zaman diliminde seyretmektedir. AKİ-6 Nisan grafiğinde ise 2014 yılında Aşırı Kurak, 2009 yılında Aşırı Nemli bir dönem meydana gelmiştir. Ayrıca tüm istasyonlar açısından 1998 ve 2002 yıllarında Şiddetli Nemli dönemler gözlemlenebilmektedir.

12 aylık dönemin izlenmesi için yapılan AKİ-12 değerlerine göre 2005 ve 2014 yıllarında Şiddetli Kuraklık gözlenirken, 2009 ile 2015 yıllarında Şiddetli Nemli dönemler tespit edilmiştir (Şekil 5). 2009 yılında Aşırı Nemli ve Aşırı Kurak dönemlere pek rastlanılmamıştır. Ölçeklendirilen zaman dilimleri birlikte incelendiğinde kuraklığın en fazla gözlemlendiği yıl 2014, nemliliğin en fazla olduğu yıl ise 2009 olarak dikkat çekmektedir.

AKİ-12

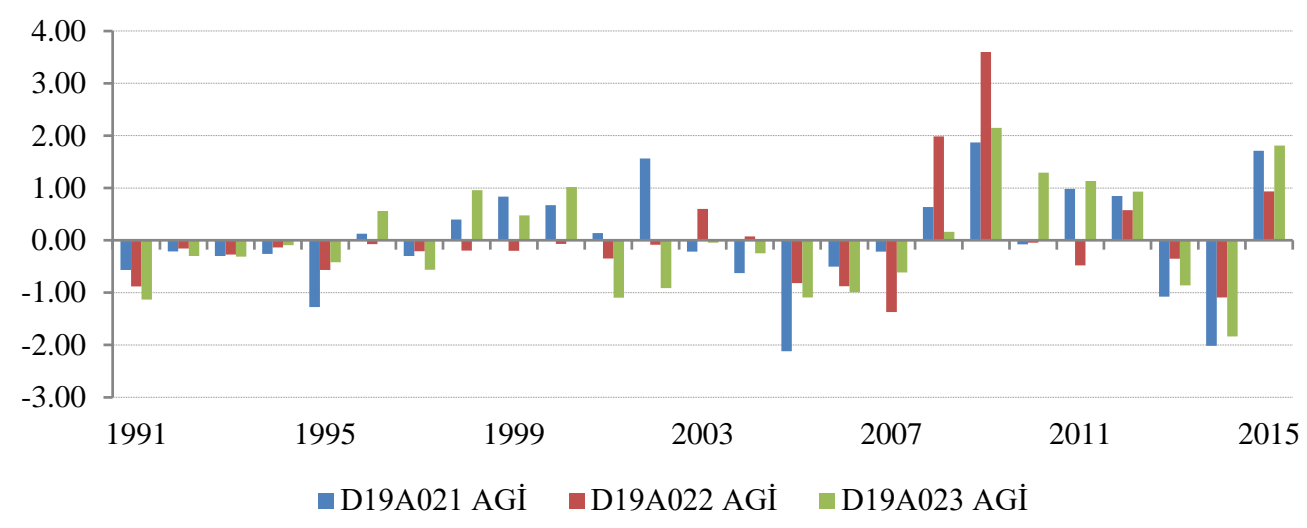

Şekil 5: AKI-12 değerlerinin 1991-2015 su yıllarına göre dağııımı

1991-2015 Su yılları arasında gerçekleşen hidrolojik kurak dönemlerin tespiti için hesaplanan AKİ değerlerine göre çeşitli istasyonlardaki kurak yıl sayıları Tablo 3'te gösterilmektedir. Toplam kurak yıl sayıları karşılaştırıldığında en çok D19A022 numaralı istasyonda kuraklık gözlemlenmiştir. Ayrıca üç istasyon arasından D19A021 numaralı istasyonda her üç zaman dilimi için de en az kuraklığın olduğu görülebilmektedir.

Tablo 3: Kurak yıl sayılarının AGi'lere göre dağııımı

\begin{tabular}{|c|c|c|c|c|c|c|c|}
\hline & $\begin{array}{l}\text { AKI-3 } \\
\text { (Ekim) }\end{array}$ & $\begin{array}{l}A K \dot{I}-3 \\
(O c a k)\end{array}$ & $\begin{array}{c}A K \dot{I}-3 \\
(\text { Nisan) }\end{array}$ & $\begin{array}{c}A K \dot{I}-3 \\
\text { (Temmuz) }\end{array}$ & $\begin{array}{l}\text { AKI-6 } \\
(\text { Ekim) }\end{array}$ & $\begin{array}{c}\text { AKİ-6 } \\
\text { (Nisan) }\end{array}$ & $A K \dot{I}-12$ \\
\hline $\begin{array}{c}D 19 A 021 \\
A G \dot{I}\end{array}$ & 11 & 14 & 11 & 12 & 10 & 12 & 14 \\
\hline $\begin{array}{c}D 19 A 022 \\
A G \dot{I}\end{array}$ & 15 & 17 & 13 & 9 & 17 & 11 & 19 \\
\hline $\begin{array}{c}D 19 A 023 \\
A G \dot{I}\end{array}$ & 13 & 13 & 12 & 14 & 12 & 13 & 15 \\
\hline
\end{tabular}

Üç farklı zaman dilimine ayrılarak oluşturulan AKİ değerlerinde kuraklık ve nemlilik için sınır şartı $\mp 0.5$ olarak geçmektedir. AKİ değeri $\mp 0.5$ arasında ise normal kabul edilirken, 0.5 'ten büyük olması halinde nemli ve -0.5 'ten küçük olması durumunda kurak olarak sınıflandırılmıştır (Gümüş vd. 2018). Şekil 6'da bu sınıflandırma koşullarından faydalanarak Arsuz Ovası'nda yer alan D19A021, D19A022 ve D19A023 numaralı istasyonlar için belirlenen Kurak/Normal/Nemli durumların yüzde dağılımları gösterilmiştir.

AKİ-3 Ekim için bulunan değerlere bakıldığında \%48 ile en kurak dönem D19A021 istasyonunda, en nemli dönem ise \%40 ile D19A022 numaralı istasyonda görülmüştür. Gümüş (2017) çalışmasında havzanın baz istasyonu ve diğer havza genelini yansıtan AGİ'ler için bu değeri yaklaşı \%30 mertebelerinde tespit etmiştir. Dolayısı ile bu zaman ölçeği için yüksek bir kuraklık yüzdesi gerçekleştiği dikkat çekmektedir. AKİ-3 Ocak değerleri incelendiğinde en kurak dönemlerin D19A023 istasyonunda, en nemli dönemlerin ise \%28 değeriyle D19A021 istasyonunda olduğu gözlemlenmiştir. AKİ-3 Nisan ölçeğinde D19A021 ile D19A023 istasyonları \%32 ile aynı en nemli döneme sahiptir. AKİ-3 Nisan değerlerinden yola çıkılarak en kurak dönem \%36 ile D19A023 istasyonunda belirlenmiştir. AKİ-3 Temmuz değerleri göz önüne alındığında ise en kurak dönemin \%44 ile en nemli dönemin ise \%40 ile aynı istasyona yani D19A021 istasyonuna ait olduğu görülebilir. 


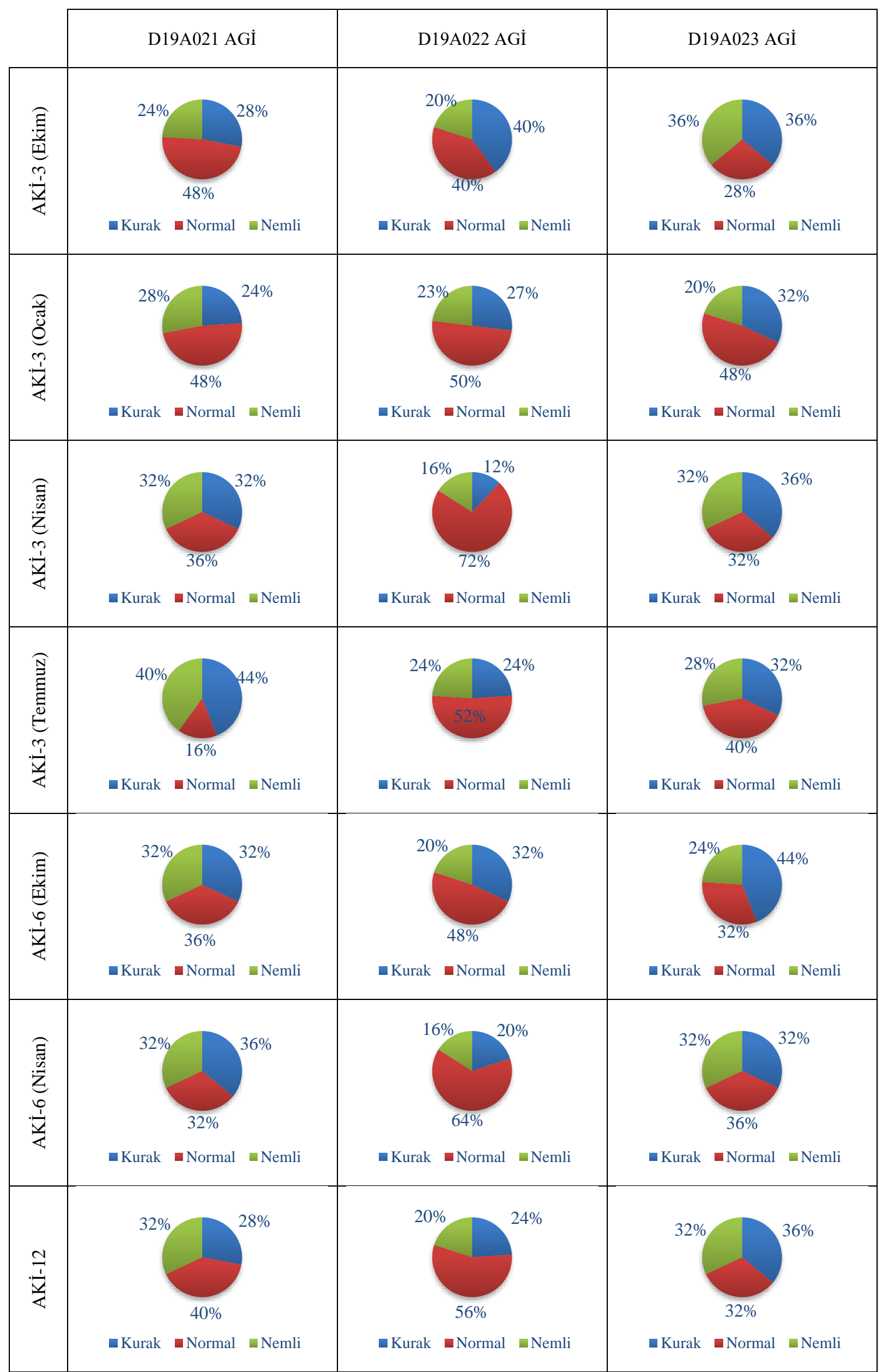

Şekil 6: Farklı zaman ölçeklerindeki AKI değerlerinin her üç istasyonda kurak/normal/nemli olarak yüzde (\%) dağılımları 
AKİ-6 Ekim yüzdeleri incelendiğinde en yüksek kuraklık oranının \%44 ile D190A23 istasyonunda, en nemli dönemin ise \%32 ile D19A021 numaralı istasyonda olduğu görülmüştür. AKİ-6 Nisan ölçeğinde D19A022 istasyonunda daha çok Normal dönem dikkat çekerken, en nemli dönem \%32 ile hem D19A021 hem de D19A023 istasyonlarında gözlenmiştir. AKİ-12 dönemlerinde de benzer değerler göze çarpmaktadır. Yine bu dönem için tüm istasyonlara bakıldığında birbirine yakın değerlerin olduğu görülebilir. Sonuçta D19A022 istasyonunda diğer iki istasyona kıyasla daha az kurak dönemin olduğu belirtilebilir. Asi Nehri Havzası genelini yansıtan çalışmalarla kıyaslandığında Arsuz Ovası için AKİ-6 Ekim döneminde yüksek kuraklık oranları görülebilir (Gümüş 2017). D19A021, D19A022 ve D19A023 numaralı istasyonlarda Nemli ya da Kurak dönem meydana gelme oranlarını tüm sınıflandırmalarla birlikte Şekil 7'deki grafiklerde görebilmek mümkündür.
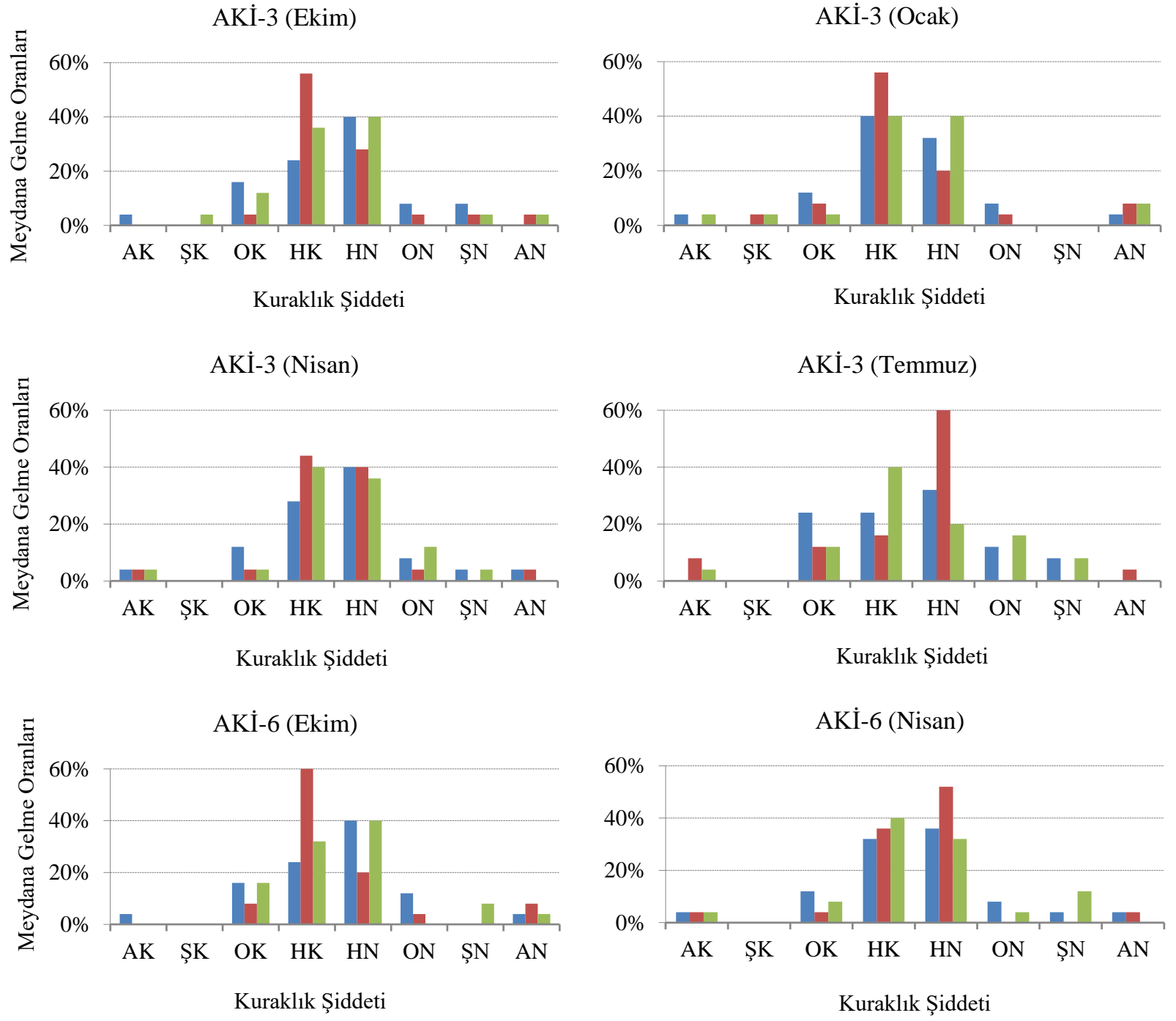

AKİ-12

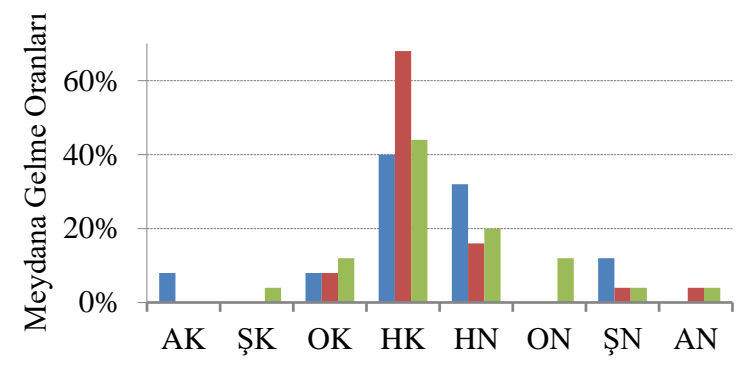

Kuraklık Şiddeti

•D19A021 AGİ -D19A022 AGİ - D19A023 AGİ

Şekil 7: Arsuz Ovası'nda belirlenen AGi'lerdeki kurak/nemli durumların meydana gelme yüzdeleri (\%) 
Her üç istasyon için grafikler ele alındığında kuraklık şiddeti olarak Hafif Kurak ve Hafif Nemli dönemlerin meydana gelme oranlarının daha yüksek olduğu görülmüştür. Tüm AKİ-3 dönemlerinde Aşırı Kurak ve Aşırı Nemli dönem \%10'nun altında seyretmiştir. AKİ-3 Nisan ile AKİ-3 Temmuz dönemlerinde Şiddetli Kuraklığın meydana gelme yüzdesi çok düşük çıkmıştır. Ayrıca AKİ-6 Ekim ve Nisan dönemlerinde de Şiddetli Kuraklık gözlenmemiştir. AKİ-6 Ekim için Aşırı Kurak dönemin meydana gelme oranı yaklaşık \%3 dolaylarındadır. AKİ-6 Nisan için ise Aşırı Kurak ve Aşırı Nemli dönemin meydana gelme oranının \%5' in altında kaldığı dikkat çekmektedir. AKİ-12 yüzdeleri incelendiğinde Aşırı Kurak dönemin meydana gelme oranı yaklaşık \% 7 olarak görülebilir. Gümüş (2017) çalışmasında ele aldığı AGI'lere göre Aşırı Kurak meydana gelme oranının \%3 civarında, Şiddetli Kuraklığın \%5, Orta Kuraklığın ise yaklaşık \%10 civarında oluştuğunu ifade etmiştir. Dolayısı ile Aşırı Kurak dönemlerin meydana gelme yüzdeleri birbirine oldukça yakın çıkmıştır.

TOB (2019)'da SPI-3, SPI-6 ve SPI-12 zaman ölçekleri için 2013-2014 yılları arasında Şiddetli Kuraklık durumunun ortaya çıktığı belirtilmektedir. Yağış verilerine bağlı düşüşler meteorolojik kuraklığın açığa çıkmasına sebep olmuştur. Devamında meydana gelen toprak suyu açığı bitki su stresini ve ürün miktarlarındaki azalmaları beraberinde getirmiştir. Tarımsal kuraklığın değerlendirildiği indeksler yardımıyla aynı çalışmada 2000-2001, 2004-2005 ve 2014 yıllarında kurak dönemler tespit edilmiştir. Azalan yüzeysel akış, hazne, göl ve sulak alanların etkisiyle çevresel, ekonomik ve sosyal etkiler söz konusu olmuştur. SPI'nin farklı zaman ölçekleri açısından Aşırı Nemli dönemleri 2007-2010 yılları arasına ve 2015 yılına denk gelmektedir. Bu çalışmada 2000 yılından sonra AKİ yöntemi ile yapılan değerlendirmelerde Aşırı Kurak ve Nemli dönemlerin söz konusu TOB (2019) sonuçları ile benzer olduğu görülebilmektedir. Altın vd. (2020) yaptıkları çalışmada hidrolojik kuraklığın meteorolojik ve tarımsal kuraklıktan sonra ortaya çıkmasının ciddi bir su açığına sebep olabileceği ve de tarımın etkin olduğu havzalarda bu durumun çözülmesi gereken önemli bir sorun olduğu ifade edilmektedir. Arsuz Ovası alüvyonlu toprakları ile verimli alanlara sahip olması sebebiyle kuraklık, bu bölgede yürütülen tarım faaliyetleri açısından önemli bir tehdit olarak düşünülebilir.

Dikici (2020) yaptığı çalışmada Asi Nehri Havzası'nda Ondalıklar İndeksi (DI) yöntemine göre Şiddetli Kuraklık görülme oranını Arsuz Ovası için \%10 dolaylarında ifade etmektedir. SPI yöntemine göre ise Hafif Kuraklık görülme oranı yaklaşık \%8 ile yine Arsuz Ovası'na aittir. Yağış azlığına rağmen bölgedeki tarımsal faaliyetlerin kuraklık etkisini düşürdüğüne dikkat çekmiştir. Ovada 5 ve 10 yıl tekerrür edebilecek Orta Kuraklık, 50 yılda bir Şiddetli Kuraklık yaşanılabileceğini vurgulamaktadır. Bu çalışmada elde edilen sonuçlar belirli zamanlarda Aşırı Kurak ve Nemli dönemlerin yaşandığını, kurak dönem sayılarında da incelenen aralığın sonlarında artışlar olduğunu göstermektedir. Dolayısı ile bu şekilde farklı indekslerden elde edilen bilgilerin kuraklığın etkilerine ilişkin risklerin yönetilmesi amacıyla önemli karar destek araçları olarak ele alınabileceği önemli bir ayrıntı olarak değerlendirilmektedir.

\section{Sonuçlar}

Asi Nehri Havzası'nda tarımsal sit alanlarından biri olan Arsuz Ovasındaki kuraklığı inceleyebilmek adına öncelikle D19A021, D19A022 ve D19A023 numaralı üç akım gözlem istasyonunun 1990-2015 y1lları arası aylık ortalama akım verileri ile debi-zaman ve debi süreklilik eğrileri (DSE) oluşturulmuştur. Özellikle 2009 yılında tüm istasyonlar için akım en yüksek değerde ortaya çıkmış, 2014 yılında ise minimum değerlere kadar düşüş göstermiştir. D19A022 AGİ için \%50 oranında DSE aşılma yüzdesi diğer istasyonlara göre daha az akım değerlerinde gerçekleşmiştir. Akım verileri belirlenen zaman aralığında Akım Kuraklık İndeksi (AKİ) yönteminde değerlendirilerek 3, 6 ve 12 ay gibi farklı zaman ölçekleri için kuraklık indis değerleri elde edilmiştir. Elde edilen tüm AKİ zaman ölçekleri için 2014 yılının en fazla kuraklık gözlemlenen yıl olduğu ve en fazla nemliliğin 2009 yılında gerçekleştiği tespit edilmiştir.

Dönemsel olarak akım değerinin en yoğun olarak gözlemlendiği AKİ-3 Ocak’ta 2005 yılına kadar en kritik durumda bile sadece Orta Kurak ya da Orta Nemli dönemler meydana gelirken, 2005 yılından itibaren bu dengenin bozulmasıyla Aşırı Nemli ve Aşırı Kurak dönemlerin oluşmaya başladığı söylenebilir. AKİ-6 Ekim dönemi için 2009 ve 2010 yıllarında Aşırı Nemli durum gözlenirken, 2005 yılında ise D19A021 numaralı AGİ'de Aşırı Kurak dönemin oluştuğu dikkat çekmiştir. AKİ-12 değerlerine göre ise kuraklık en fazla \%36 ile D19A023 numaralı istasyonda tespit edilmiştir. AKİ-3 Nisan, AKİ-6 Nisan ve AKİ-12 dönemlerinde D19A021 ve D19A023 numaralı istasyonlarda nemli durumu sağlayan AKİ değerleri \%32 ile benzer çıkmıştır. Bütün AKİ dönemleri birlikte göz önüne alındığında ise D19A022 numaralı istasyonda kuraklığın meydana gelme oranı diğer iki istasyona göre oldukça azdır. Her üç istasyonun aylık akım verileri kullanılarak oluşturulan istatistiksel ilişkiler değerlendirildiğinde birbirine yakın sonuçların olduğu görülmüş, AKİ'nin farklı zaman ölçekleri için aynı istatistiki hesaplar göz önüne alındığında ise akım verilerine benzer şekilde D19A021 ve D19A023 istasyonları arasında daha yüksek bir korelasyon gözlemlenmiştir.

Sonuç olarak küresel iklim değişikliği ve kuraklığa karşı alınabilecek önlemler, planlama ve risk yönetimi konularında yapılan çalışmaların hâlâ geliştirilmesinin gerekliliği ortadadır. Bu süreçte su kaynakları mühendisliği açısından uygun eylem planlarının hazırlanması uzun vadede düşünülmesi önem arz eden başlıklardandır. Özellikle meteorolojik, tarımsal ve hidrolojik kuraklık çalışmalarının geniş bir alanı kapsayacak şekilde ele alınması gerekmektedir. Böylece kuraklığın meydana getirebileceği olumsuz etkiler ciddi derecede azaltılabilecektir. İleride bu çalışma kapsamında ele alınan Arsuz Ovası gibi tarımsal anlamda önemli farklı stratejik bölgesel kuraklık izleme, trend analizleri ve gelecek projeksiyon tahmin modellerinin oluşturulmasının karar verme süreçlerinde etkin rol oynayabileceği bir gerçektir. 


\section{Kaynaklar}

Adib A., Kashani, A., Ashrafi S.M., (2020), Merge L-Moment method, regional frequency analysis and SDI for monitoring and Zoning map of short-term and long-term hydrologic droughts in the Khuzestan Province of Iran, Iranian Journal of Science and Technology, Transactions of Civil Engineering, 45(4), 2681-2694.

Aghelpour P., Bahrami-Pichaghchi H., Varshavian V., (2021), Hydrological drought forecasting using multi-scalar streamflow drought index, stochastic models and machine learning approaches, in northern Iran, Stochastic Environmental Research and Risk Assessment, 35, 1615-1635.

Altın T.B., Sarış F., Altın B.N., (2020), Determination of drought intensity in Seyhan and Ceyhan River Basins, Turkey, by hydrological drought analysis, Theoretical and Applied Climatology, 139(1), 95-107.

Arslan O., Önder H.H., Özdemir G., (2014), Aydeniz yöntemi ve Coğrafi Bilgi Sistemleri ile Antalya'daki Aksu sulama alanı için kuraklık analizi, Ege Üniversitesi Ziraat Fakültesi Dergisi, 51(2), 109-115.

Başakın E.E., Ekmekçioğlu Ö., Özger M., (2019), Makine ögrenmesi yöntemleri ile kuraklık analizi, Pamukkale Üniversitesi Mühendislik Bilimleri Dergisi, Uluslararası Kentsel Su ve Atıksu Yönetimi Sempozyumu (UKSAY)-2018 Özel Sayıs1, 25(8), 985991.

Dai M., Huang S., Huang Q., Leng G., Guo Y., Wang L., Fang W., Li P., Zheng X., (2020), Assessing agricultural drought risk and its dynamic evolution characteristics, Agricultural Water Management, 231, 106003. doi: 10.1016/j.agwat.2020.106003.

Dikici M., (2019), Asi Havzası'nda (Türkiye) Kuraklık Analizi, Doğal Afetler ve Çevre Dergisi, 5(1), 22-40.

Dikici M., (2020), Drought analysis with different indices for the Asi Basin (Turkey), Scientific Reports, 10, 20739, doi: 10.1038/s41598-020-77827-z.

DSİ, (2018), Akım gözlem yıllıkları (1959-2015), Etüd Plan Dairesi, Ankara.

Eriş E., Aksoy H., Onoz B., Çetin M., Yüce M.İ., Selek B., Aksu H., Burgan H.İ., Eşit M., Yıldırım I., Karakuş E.U., (2019), Frequency analysis of low flows in intermittent and non-intermittent rivers from hydrological basins, in Turkey, Water Science and Technology: Water Supply, 19(1), 30-39.

Eriş E., Çavuş Y., Aksoy H., Burgan H.İ., Aksu H., Boyacıŏlu H., (2020), Spatiotemporal analysis of meteorological drought over Kucuk Menderes River Basin in the Aegean Region of Turkey, Theoretical and Applied Climatology, 142(3), 1515-1530.

Eroğluer T.A., Apaydın H., (2020), Estimation of drought by streamflow drought index (SDI) and artificial neural networks (ANNs) in Ankara-Nallihan region, Turkish Journal of Agriculture - Food Science and Technology, 8(2), 348-357.

Gümüş V., (2017), Akım kuraklık indeksi ile Asi havzasının hidrolojik kuraklık analizi, Gazi Üniversitesi Fen Bilimleri Dergisi Part C: Tasarım ve Teknoloji, 5(1), 65-73.

Gümüş V., Algin, H.M., (2017), Meteorological and hydrological drought analysis of the Seyhan-Ceyhan River basins, Turkey, Meteorological Applications, 24(1), 62-73.

Gümüş V., Yıldız M.S., Şimşek O., (2018), Hidrolojik Kuraklık Değerlendirmesi: Murat Nehri-Palu Örneği, Harran Üniversitesi Mühendislik Dergisi, 3(3), 297-301.

Hong X., Guo S., Zhou Y., Xiong L., (2015), Uncertainties in assessing hydrological drought using streamflow drought index for the upper Yangtze River basin, Stochastic Environmental Research and Risk Assessment, 29(4), 1235-1247.

Jahangir M.H., Yarahmadi Y., (2020), Hydrological drought analyzing and monitoring by using streamflow drought index (SDI) (case study: Lorestan, Iran), Arabian Journal of Geosciences, 13(3), 110. doi: 10.1007/s12517-020-5059-8.

Keskiner A.D., Çetin M., Akın S., Şimşek M., (2019), Erinç kuraklık indeksi yöntemiyle iklim tipi eğilimlerinin analizi: Güneydoğu anadolu projesi (GAP) alaninda bir uygulama, 10. Ulusal Hidroloji Kongresi, 9-12 Ekim, Muğla Sitk1 Koçman Üniversitesi, Muğla, ss.403-414.

Keskiner A.D., Çetin M., Şimşek M., Akın S., (2020), Kuraklık riski altındaki havzalarda gölet haznelerinin tasarımı: Seyhan havzasi'nda bir uygulama, Teknik Dergi, 31(5), 10189-10210.

Kılıç E., (2017), Asi havzasındaki su kalitesinin çok değişkenli istatistiksel yöntemler kullanılarak değerlendirilmesi, Yüksek Lisans Tezi, İskenderun Teknik Üniversitesi, Mühendislik ve Fen Bilimleri Enstitüsü, Hatay.

Kumanlığlu A.A., (2020), Hydrological droughts and runoff trends of the Demirköprü dam reservoir basin on Gediz River, Turkey, Dokuz Eylül Üniversitesi Mühendislik Fakültesi Fen ve Mühendislik Dergisi (DEÜ FMD), 22(6), 793-800.

Nalbantis I., (2008), Evaluation of a hydrological drought index, European Water, 23(24), 67-77.

Oğuz K., Pekin M.A., Çamalan G., (2021), Muğla İlinde 1960-2018 Dönemi Kuraklık Analizi, Doğal Afetler ve Çevre Dergisi, 7(1), 89-100.

Özcan M., Gümüş V., Şimşek O., Şeker M., (2019), Drought analysis of Bitlis river Baykan station with streamflow drought index (SDI) method, 7th International Symposium on Innovative Technologies in Engineering and Science, 22-24 November, Şanliurfa, Türkiye, Academic Perspective Procedia, 2(3), 1100-1106.

Özfidaner M., Topaloğlu F., Baydar A., Şapolyo D., (2015), Doğu Akdeniz havzası akım verilerinin hidrolojik kuraklık analizi :1712 nolu AGI, 4. Uluslararası Katılımlı Toprak ve Su Kaynakları Kongresi, 01-04 Eylül, Kahramanmaraş, ss.1-6.

Özfidaner M., Topaloğlu F., (2020), Standart yağış indeksi yöntemi ile güneydoğu anadolu bölgesinde kuraklık analizi, Toprak Su Dergisi, 9(2), 130-136.

Özkaya A., Zerberg Y., (2019), A 40-Year analysis of the hydrological drought index for the Tigris basin, Turkey, Water, 11(4), 657, doi: 10.3390/w11040657.

Partal T, Yavuz E., (2020), Batı Karadeniz Bölgesinde Kuraklık İndisleri Üzerine Trend Analizi Uygulanması, Doğal Afetler ve Çevre Dergisi, 6(2), 345-353.

Şener E., Şener Ş., (2021), SPI ve CZI kuraklık indislerinin CBS tabanlı zamansal ve konumsal karşılaştırması: Burdur Gölü Havzası örneği, Doğal Afetler ve Çevre Dergisi, 7(1), 41-58.

Tabari H., Nikbakht J., Talaee P.H., (2013), Hydrological drought assessment in Northwestern Iran based on streamflow drought index (SDI), Water Resources Management, 27, 137-151.

TOB, (2019), Asi ve Seyhan Havzaları taşkın ve kuraklık yönetim planlarının hazırlanması projesi, T.C. Tarım ve Orman Bakanlığı, Su Yönetimi Genel Müdürlüğü, Taşkın ve Kuraklık Yönetimi Dairesi Başkanlığı, Ankara, 70ss. 
Topçu E., Seçkin N., (2019), Drought analysis of Eastern Mediterranean, Seyhan, Ceyhan and Asi basins by using streamflow drought index (SDI), Innovation and Global Issues Congress V, May 02-04, Ankara, Türkiye.

Tosunoğlu F., İspirli M.N., Gürbüz F., Şengül S., (2017), Fırat havzası'ndaki eksik akım verilerinin debi süreklilik çizgileri ve regresyon modelleri ile tahmin edilmesi, Iğdır Üniversitesi Fen Bilimleri Enstitüsü Dergisi, 7(4), 85-94.

Uludağ B., Ağca N., (2019), Determination of spatial distribution of potassium fractions in the Arsuz plain soils using geostatistical methods, Mustafa Kemal Üniversitesi Tarım Bilimleri Dergisi, 24(3), 295-307.

Yaltı S., Aksu H., (2019), Drought analysis of I $\breve{g} d ı r$ Turkey, Turkish Journal of Agriculture - Food Science and Technology, 7(12), $2227-2232$ 